\title{
Indirect Determination of the Risk of Transportation Projects
}

O. Pastor

This paper deals with indirect determination of the risk of transportation projects. It focuses on cases when the project has certain characteristics that might lead to conclusions concerning the degree of risk. The author proposes a multi-criterion evaluation of the territory with respect to its time evolution in order to determine the characteristics. The proposed method enables a simple graphical representation of the achievement of the territorial evolution in each time section, and also in the entire period that is under consideration. The method presents an inverse characteristic of the risk of the project.

Keywords: risk, indirect determination, transportation projects.

\section{Introduction}

The financial risk of a project may be determined in numerical form, when the starting point is the determination of the probabilistic distribution of the criteria that evaluate the financial efficiency of the project. When the risk of the project is determined indirectly, unlike direct (numerical) determination of the risk, the probabilistic distribution of the criteria for evaluating the project does not have to be constructed, but certain characterization of the project must be laid down. On the basis of this characterization, the degree of risk can be estimated indirectly.

Generally, a project can be defined as a set of reciprocally adherent liaisons, actions and proceedings oriented at achieving specific project objects in a given area and within a certain period. From the point of view of the development of a certain territory (locality) the desired target is the gradual progress of the development in different time periods; globally expressed - the locality should be improved from its initial state in each time period. The targets give to each system a purpose and the direction of its motion. The target is well formulated if it includes the interest that the project pursues, and also if the desired orientation of the progress of this interest is marked.

A global formulation of the development of a certain locality is also taken into account. This development is viewed in terms of time as well as the effects and requirements of the assessed project throughout its life (development period of the territory). Thus in a certain sense there is a positive or negative influence on the environmental capacity of the locality.The area of the assessment of a project represents a rational distribution of elements that are the object of the evaluation. For practical reasons these elements are regrouped into certain blocks - the above-mentioned targets of the project - in which savings of resources appear as a benefit and the expense of resources as a cost.

The basic blocks for assessing transportation projects can comprise:

\section{Direct demand of users:}

This paragraph analyses the benefit of the implemented project for the user. The benefits may be quantified according to: subjects (individuals, transporters); areas in which the benefits emerge; type of journey (to work, for shopping). Al- ternatively, the quantification can refer to the relation to the conditions of future traffic flow (security, extent of awareness of users). The analysed benefits should also consider the possibility that the implemented project will "attract" additional transportation flow (generated by the new project or diverted from another route). This involves quantification of timesavings, petrol savings, reduction of traffic incidents, and benefits arising from the higher quality of the transportation path.

Direct and indirect demands of the transportation system:

The investment costs and also the costs of the functional provision and the efficiency of the transportation path are dealt with in this block.

\section{Indirect external influences:}

This block contains external effects and the events that accompany them. These influences reach beyond the area of the infrastructure. This refers above all to the impact on the environment, economic activities in the affected area or the recreation area. We need to quantify air pollution, noise, vibrations, together with limitations on recreation functions and regional development.

\section{Model of multi-criterion assessment of variants}

The set of targets must also be considered in relation to the assessed project and the criteria for the efficiency of the adopted decision in time. Each project is characterized by its demands and impacts. If a global indicator of the evaluation of the decision efficiency is to be constructed, it must be taken into account that this is a multidimensional category. The indicator then represents whether the selected project leads to an improvement on a deterioration of the locality. The starting point is the matrix of a multi-criterion assessment of the variants (a globally used term in multi-criterion decision theory) - see Table 1 .

The variables used in Table 1 represent:

$X \quad\left(x_{1}, x_{2}, \ldots, x_{m}\right)$ set of possible variants,

$R \quad\left(R_{1}, R_{2}, \ldots, R_{n}\right)$ set of the common characteristics of the variants (criteria, aspects),

$u_{j}\left(x_{i}\right)$ an evaluation of the $i$-th variant according to the $j$-th characteristics. 
The process of variant assessment related to the selected set of criteria determines the preferable distribution of the variants, which is a sequence of the convenience of the variants. This process usually requires complementary information about the weight of each criterion.

Table 1: Multi-criterion assessment

\begin{tabular}{|c|c|c|c|c|c|}
\hline \multirow{2}{*}{ Variants } & \multicolumn{5}{|c|}{ Characteristics } \\
\cline { 2 - 6 } & $R_{1}$ & $R_{2}$ & $\ldots$ & $R_{j}$ & $R_{n}$ \\
\hline$x_{1}$ & $u_{1}\left(x_{1}\right)$ & $u_{2}\left(x_{1}\right)$ & $\ldots$ & $u_{j}\left(x_{1}\right)$ & $u_{n}\left(x_{1}\right)$ \\
\hline$x_{2}$ & $u_{1}\left(x_{2}\right)$ & $u_{2}\left(x_{2}\right)$ & $\ldots$ & $u_{j}\left(x_{2}\right)$ & $u_{n}\left(x_{2}\right)$ \\
\hline & & & $\ldots$ & & \\
\hline$x_{m}$ & $u_{1}\left(x_{m}\right)$ & $u_{2}\left(x_{m}\right)$ & $\ldots$ & $u_{j}\left(x_{m}\right)$ & $u_{n}\left(x_{m}\right)$ \\
\hline
\end{tabular}

\section{Construction of a global expression for the development of a locality as a characteristic of the risk of the project}

From the point of view of constructing a global expression for the development of a locality, the characteristics $R_{1}, R_{2}$, $\ldots, R_{n}$ are assumed to be expert expressions of the evaluating aspects of exogenously submitted targets. In other words, the characteristics are aspects (indicators) that characterize the demands and effects as a result of the implementation of a certain variant of the project that influences the development of a given locality.

Let us attach to the term "project" a set of evaluating aspects of the locality $R_{1}, R_{2}, \ldots, R_{n}$. The impact of the efficiency of the implemented solution must be shown in the assessment of the global efficiency of the whole period of development RO. Each submitted period (time section) is indicated by $1,2, \ldots, T$. The degree of fulfilment of each evaluating aspect is known for each of these periods and is expressed as follows:

$$
x_{1}(1), x_{2}(1), \ldots, x_{n}(T),
$$

measured on a cardinal or ordinal scale (some of the data may be missing). Expressed by Table 2 .

Table 2. Evaluation period

\begin{tabular}{|c|c|c|c|c|}
\hline \multirow{2}{*}{ Period } & \multicolumn{4}{|c|}{ Evaluating criteria } \\
\cline { 2 - 5 } & $R_{1}$ & $R_{2}$ & $\ldots$ & $R_{n}$ \\
\hline 1st period & $x_{1}(1)$ & $x_{2}(1)$ & $\ldots$ & $x_{n}(1)$ \\
\hline & & & $\ldots$ & \\
\hline$T$ th period & $x_{1}(T)$ & $x_{2}(T)$ & $\ldots$ & $x_{n}(T)$ \\
\hline
\end{tabular}

Variable $x_{j}(i)$ in Table 2 indicates the degree of fulfilment of the $j$-th evaluating criterion in the $i$-th period.

From the value of $x_{j}(i)$ we may be guess whether or not the development of the locality is successful in relation to the chosen project (in terms of improving the locality). This involves a multi-criterion assessment of the variants, where the variants represent time periods in evaluating the locality, and the characteristics constitute the evaluating aspects of the development of the locality.

The output of some of the methods of multi-criterion evaluation (ELECTRA IV) is an ordered list of variants, from the best to the worst. The order is represented graphically and a global indicator of the development of the locality is obtained. Four different courses of the order of each period can be anticipated, as follows below. Hence, we obtain a global (graphical) expression of the efficiency of the development of the locality influenced in time by the evaluating project.

\section{a) Monotonous growth in efficiency of development of a locality}

For each pair of periods $t_{1}, t_{2} \in \mathrm{RO}, t_{1}<t_{2}$, such that order $t_{1} \geq$ order $t_{2}$ :

The last observed period is considered as the best, and the worst period is the first in the progressive series. Hence we can conclude that the observed project has a positive impact on the development of the locality (territory) and the risk is very low, arising from the positive influence on the environmental capacity of the locality (Fig. 1).

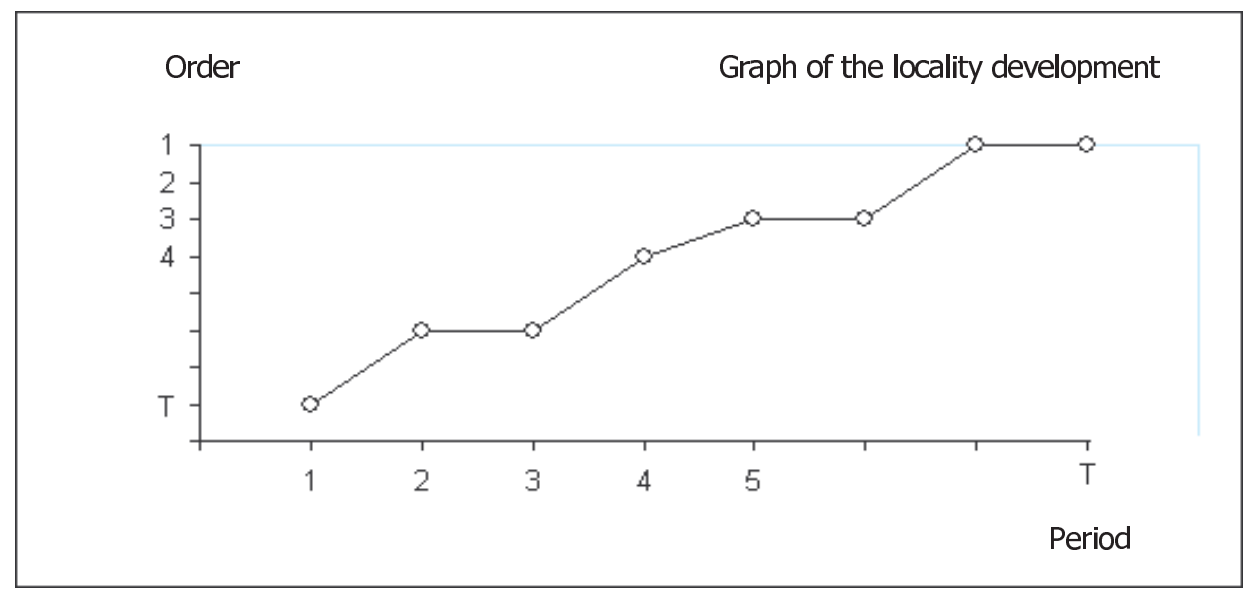

Fig. 1: Monotonous growth in efficiency 


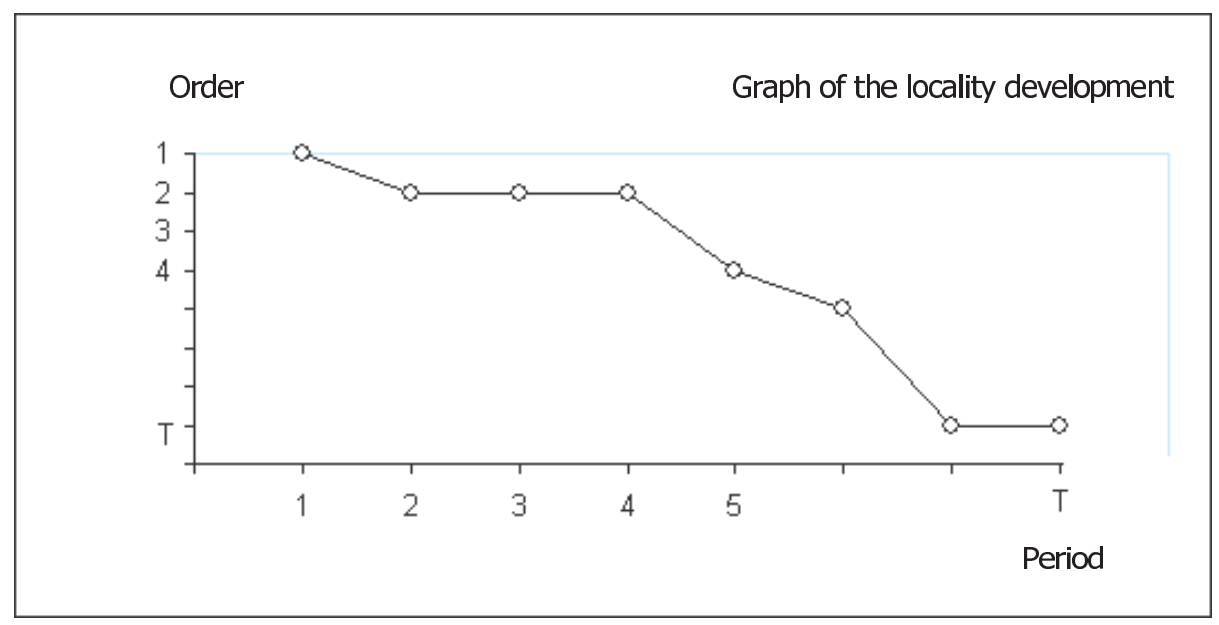

Fig. 2: Monotonous decrease in efficiency

The function of "efficient" development of a locality $f(t)$, $t=1,2, \ldots, T$, can in this and other cases be expressed, for example, by Newton's interpolation polynomial:

$f(t)=y_{1}+A_{1}(t-1)+A_{2}(t-1)(t-2)+A_{3}(t-1)(t-2)(t-3)+$

$\ldots+A_{T}(t-1)(t-2) \ldots(t-T)$,

where $y_{1}$ is the order of the first period and $A_{i}, i=1,2, \ldots, T$ are calculated constants.

\section{b) Monotonous decrease in efficiency of development of a locality}

For each pair of periods $t_{1}, t_{2} \in \mathrm{RO}, t_{1}<t_{2}$, such that order $t_{1} \leq$ order $t_{2}$ :

The first period is considered as the best, and the worst period is the last in the sequence. Hence a negative influence on the development of the locality can be assumed and the project is characterized by a high risk level, arising from the negative influence on the environmental capacity of the locality (Fig. 2).

\section{c) Extreme courses of efficiency in the development of a locality}

If there is a minimum in the course, it refers to a situation of monotonous growth in the efficiency of the development of a locality. If there is a maximum in the course, it refers to a situation of monotonous growth in efficiency until this extreme, followed by a monotonous decrease in the efficiency of the development of the locality after the extreme. It can be anticipated that the worsening situation will cause problems similar to b). Similarly for the minimum (see Fig. 3).

\section{d) Non-systematic course of efficiency of the development of a locality}

No concrete conclusion can be reached for this situation without making a deep analysis and performing experiments with a set of evaluating criteria and a simulation of combinations of resolutions, since the locality can hold more than one extreme (Fig. 4).

The courses that are obtained may serve as a starting point for an ex ante analysis of the deviations in the development of the locality from the simulated impact targets when the project was selected. The analysis should show how these deviations emerge, how the development would proceed without an intervention, how to correct the deviations, etc. The proposed method enables the user to express in a simple graphical way the "efficiency" of the development of the locality in each period and throughout the observed period, as an inverse expression of the risk of the project. As the efficiency grows, the risk decreases.

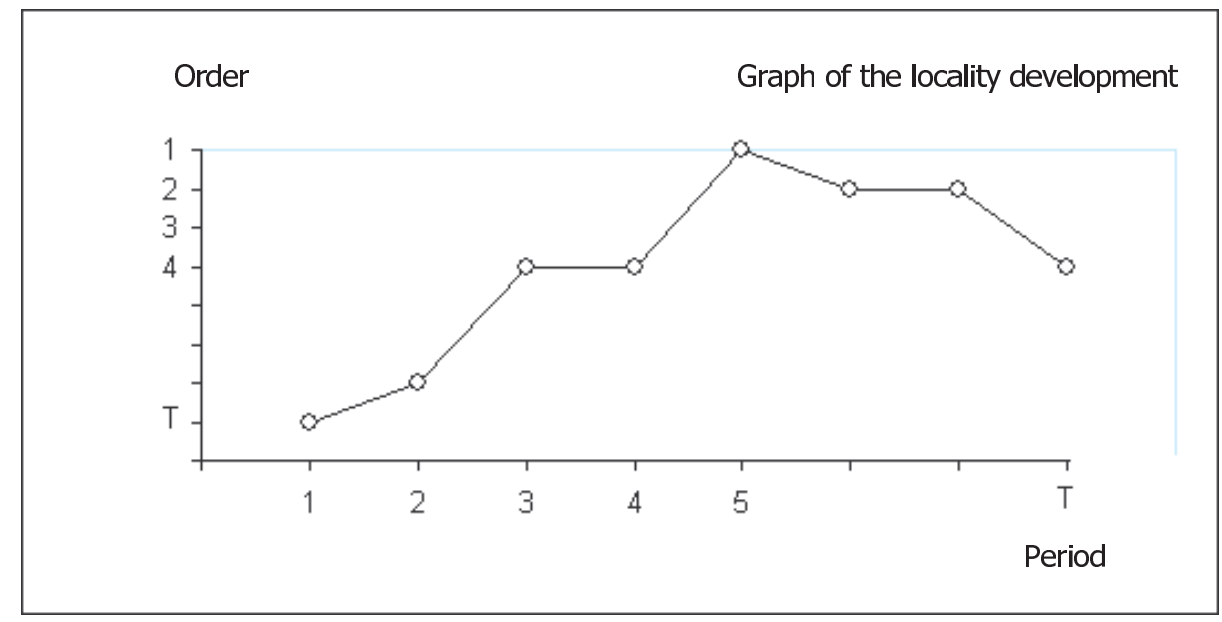

Fig. 3: Extreme courses of efficiency 


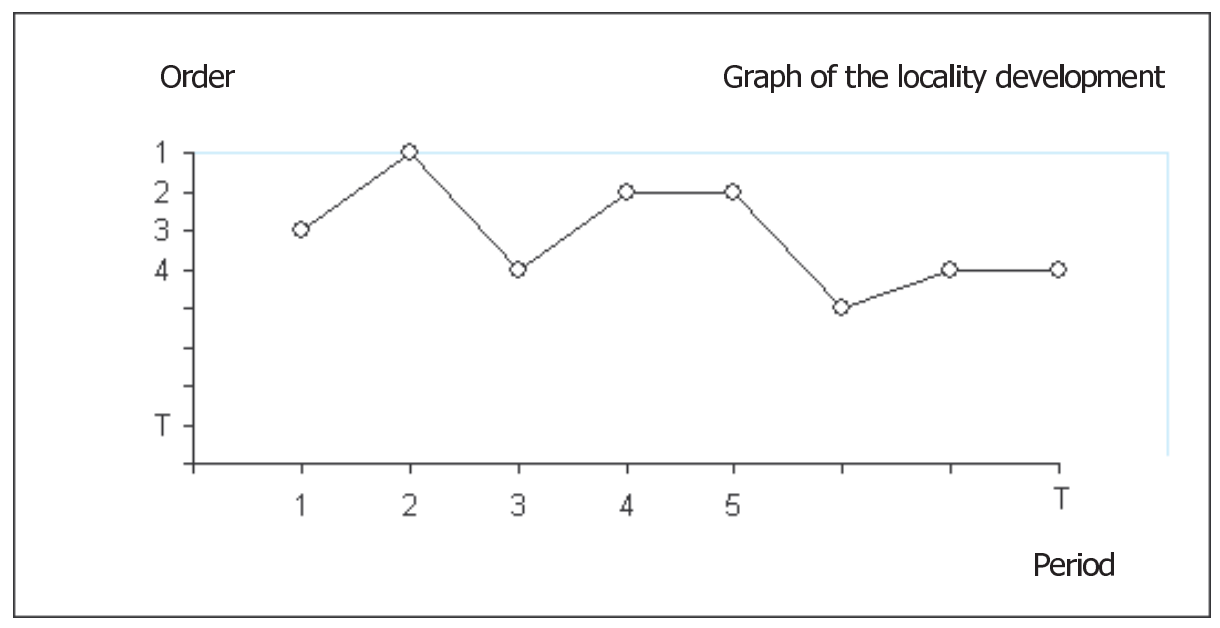

Fig. 4: Non-systematic course of efficiency

\section{Conclusions}

The evaluating criteria characterize the demands in each period and the effects that will result from implementing a project that influences a given locality in the course of its development. The targets and evaluating criteria are expressed in the "language of problems", i.e. a decision is to emerge. Different problems (types of infrastructure problems) have different languages. However the method is formally identical.

In conclusion it should be pointed out that when the risk of a project is quantified or if a characterization of the indirect determination of a project is constructed, we cannot speak of a real risk, but a risk as it appears to the team working on the problem. The analysis on its own is not a technique that can compensate for defects in the input data and in the team's informed guesswork. Nevertheless, applying our method, together with a financial analysis, brings transparency to the information concerning the project.

\section{References}

[1] Pastor, O.: Project Development Cycle - Activities and Project Documentation. In: Automatizace. Czech Republic, Vol. 44 (2001), No. 12, p. 755-756. ISSN 0005-125X.
[2] Pastor, O.: Modelling of Economic Risks in Transport Projects. In: PRONT 2000. Pilsen: University of West Bohemia, Czech Republic, 2001, p. 195-198. ISBN 80-7082-648-7.

[3] Fiala, P., Jablonský, J., Maňas, M.: Vicekriteriální rozhodování. Prague: University of Economics, Czech Republic, 1994, ISBN 80-7079-748-7.

[4] Zelený, L.: Doprava (Ekonomické souvislosti rozvoje). Prague: University of Economics, Czech Republic, 1995, ISBN 80-7079-402-X.

Doc. Dr. Ing. Otto Pastor, CSc.

e-mail: pastor@fd.cvut.cz

Department of Logistic and Transportation Processes

Czech Technical University in Prague

Faculty of Transportation Science

Horská 3

12803 Prague 2, Czech Republic 